\title{
Impact of Grid Gas Requirements on Hydrogen Blending Levels
}

\author{
Eduard LATÕŠOV ${ }^{1 *}$, Ieva PAKERE ${ }^{2}$, Lina MURAUSKAITE ${ }^{3}$, Anna VOLKOVA ${ }^{4}$ \\ ${ }^{1,4}$ Tallinn University of Technology, Ehitajate tee 5, 19086, Tallinn, Estonia \\ ${ }^{2}$ Riga Technical University, 1 Kalku Street, Riga, LV-1658, Latvia \\ ${ }^{3}$ Lithuanian Energy Institute, Breslaujos St. 3, LT-44403, Kaunas, Lithuania
}

\begin{abstract}
The aim of the article is to determine what amount of hydrogen in \%mol can be transferred/stored in the Estonian, Latvian and Lithuanian grid gas networks, based on the limitations of chemical and physical requirements, technical requirements of the gas network, and quality requirements. The main characteristics for the analysis of mixtures of hydrogen and natural gas are the Wobbe Index, relative density, methane number, and calorific value. The calculation of the effects of hydrogen blending on the above main characteristics of a real grid gas is based on the principles described in ISO 6976:2016 and the distribution of the grid gas mole fraction components from the grid gas quality reports. The Wärtsila methane number calculator was used to illustrate the effects of hydrogen blending on the methane number of the grid gas. The calculation results show that the maximum hydrogen content in the grid gas (hydrogen and natural gas mix), depending on the grid gas quality parameters (methane number, gross heat of combustion, specific gravity, and the Wobbe Index), is in the range of 5-23\% \%ol $\mathrm{H}_{2}$. The minimum hydrogen content $\left(5 \% \mathrm{~mol} \mathrm{H}_{2}\right)$ is limited by specific gravity $(>0.55)$. The next limitation is at $12 \% \mathrm{~mol}_{2}$ and is related to the gross heat of combustion $\left(>9.69 \mathrm{kWh} / \mathrm{m}^{3}\right)$. It is advisable to explore the readiness of gas grids and consumers in Estonia, Latvia and Lithuania before switching to higher hydrogen blend levels. If the applicability and safety of hydrogen blends above $5 \% \mathrm{~mol}$ is approved, then it is necessary to analyse the possible reduction of the minimum requirements for the quality of the grid gas and evaluate the associated risks (primarily related to specific gravity).
\end{abstract}

Keywords - Green gas; $\mathrm{H}_{2}$; natural gas; relative density; Wobbe Index

\begin{tabular}{|lll|}
\hline \multicolumn{2}{|l|}{ Nomenclature } & \\
$\rho^{\text {air }}{ }_{m}$ & Air density at reference measuring conditions & $\mathrm{kg} / \mathrm{m}^{3}$ \\
$\rho^{\text {ideal }}{ }_{n}$ & Ideal gas density under reference measuring conditions & $\mathrm{m} / \mathrm{kmol}$ \\
$\rho^{\text {real }}{ }_{m}$ & Real gas density under reference measuring conditions & $\mathrm{m} / \mathrm{kmol}$ \\
$c_{i}$ & Mole fraction of component $i$ & \\
$G s$ & Specific gravity & \\
$H_{e i}$ & Ideal gross calorific value on a molar basis of component $i$ & \\
$H_{\text {mole }}^{\text {ideal, gross }}$ & Ideal-gas gross calorific value on a molar basis of the grid gas mixture & $\mathrm{kJ} / \mathrm{mol}$ \\
$H_{\text {mole }}^{\text {real, gross }}$ & Real-gas gross calorific value on a molar basis of the grid gas mixture & $\mathrm{kJ} / \mathrm{mol}$ \\
$H_{\text {vol }}^{\text {real, gross }}$ & Real-gas gross calorific value on a volume basis of the grid gas mixture & $\mathrm{kWh} / \mathrm{m}^{3}$ \\
\hline
\end{tabular}

${ }^{*}$ Corresponding author.

Email address: eduard.latosov@taltech.ee 


\begin{tabular}{|llc|}
\hline$I_{w}$ & Wobbe Index & $\mathrm{g} / \mathrm{mol}$ \\
$M_{\text {air }}$ & Molar composition of reference air & $\mathrm{g} / \mathrm{mol}$ \\
$M_{C}$ & Molar mass of carbon & $\mathrm{g} / \mathrm{mol}$ \\
$M_{H}$ & Molar mass of hydrogen & $\mathrm{g} / \mathrm{mol}$ \\
$M_{i}$ & Molar mass of component $i$ & $\mathrm{~g} / \mathrm{mol}$ \\
$M_{N}$ & Molar mass of nitrogen & $\mathrm{g} / \mathrm{mol}$ \\
$M_{O}$ & Molar mass of oxygen & $\mathrm{kPa}$ \\
$p_{0}$ & Absolute pressure & $\mathrm{kPa}$ \\
$p_{m}$ & Pressure (reference measuring conditions) & $\mathrm{J} /(\mathrm{mol} \cdot \mathrm{K})$ \\
$R$ & Universal gas constant & \\
$S_{i}$ & Summation factor at reference measuring conditions & \\
$Z_{a i r, m}$ & Compression factor of dry air of reference composition at reference & \\
$Z_{i}$ & measuring conditions & \\
$Z_{m}$ & Number of nitrogen atoms in the component $i$ formula & ${ }^{\circ} \mathrm{C}$ \\
$t_{m}$ & Compression factor under reference measuring conditions & $\mathrm{m} 3 / \mathrm{kmol}$ \\
$V_{M}$ & Temperature (reference measuring conditions) & \\
$W_{i}$ & Molar volume of gas under normal conditions & \\
$X_{i}$ & Number of oxygen atoms in the component $i$ formula & \\
$Y_{i}$ & Number of carbon atoms in the component $i$ formula & \\
\hline
\end{tabular}

\section{INTRODUCTION}

In accordance with the objectives of the climate policy of the European Union and due to the likely commissioning of large-scale inverter-based power generation equipment, it may be necessary to store energy in the gas network in the form of hydrogen and synthetic methane [1].

The process of feeding hydrogen and synthetic gas into the transmission network of the natural gas steel pipeline has become a pressing issue in Europe over the past decade, and the related challenges and options have become more apparent lately [2]-[7].

The scientific review explores how the natural gas system can aid in the transition to longterm use of hydrogen blending by adding renewable hydrogen to the NG system. Hydrogen blending in the NG pipeline grid is considered technically feasible at moderate fractions, but requires careful case-by-case assessment and can be expensive [8].

There are real-life projects related to the injection of hydrogen into natural gas networks in different countries, including France [9], Germany [10], Denmark, Switzerland, Canada, and the Netherlands [6].

In Latvia, an analysis of the introduction of hydrogen into the natural gas network via blending showed that the barriers include a hydrogen threshold that is too low $(0.1 \mathrm{vol} \%)$ and a section of the existing NG network that is unsuitable for transporting hydrogen with the oldest pipes from 1967 [11]. The results of another study [12] showed that each element of natural gas infrastructure has a different degree of acceptability for hydrogen concentration: the limit value of $10 \%$ hydrogen admixture for the transmission network, $50 \%$ concentration for distribution network and storage elements, 20-50\% for end-use appliances. This research paper included a case study that showed that hydrogen injection affects the quality of the gas 
in the supply nodes: the introduction of $2 \%$ hydrogen into the distribution network has little effect, but the $10 \%$ hydrogen mixture affects the calorific value of the supplied fuel gas, dropping it below the desired level [12].

Due to the difference between hydrogen and natural gas, mixtures of hydrogen and natural gas create additional hazards, causing corrosion and increasing the risk of explosion and fire in pipelines and end-user installations.

By its nature, hydrogen is lighter than natural gas and air, and its leakage from the pipeline is about 1.3-2.8 times greater that the leakage of methane, and four times more than the leakage of air under the same conditions [13]. The dispersion of hydrogen in air is greater than in the case of natural gas. Because of this, the addition of hydrogen makes the mixture lighter with a higher diffusion coefficient and a higher volumetric flow rate compared to methane at the same pressure and size of the leak [14].

Hydrogen and natural gas are flammable gases. Knowing flammability limits is crucial to implementing appropriate safety measures. The main hazards associated with hydrogen installations are fires and explosions caused by uncontrolled separation and ignition. Although self-ignition is possible with any flammable gas, hydrogen is rather specific in regard to this phenomenon. The reason is the low flash energy of hydrogen and the fact that, unlike most gases, the temperature of hydrogen increases as it expands from higher to lower pressure [15].

In a confined environment, hydrogen leakage of any size is problematic as humans cannot detect hydrogen and it can become flammable in air over a very wide concentration range. Besides, hydrogen burns with a light-blue flame that is invisible in daylight, there is no smoke and the flame emits less heat than hydrocarbons.

Gas detection devices designed for natural gas processing can be insensitive to several mixtures of natural gas and hydrogen, including pure hydrogen. Adding hydrogen to natural gas reduces the mixture's ability to emit thermal radiation (the higher the hydrogen content, the lower it is) [14]. Therefore, the combustion of hydrogen (fire) and its spread cannot be detected [16].

The hydrogen addition restrictions include the quality requirements for gases fed into the natural gas network. Synthetic methane, which is the result of methanation (conversion of $\mathrm{CO}_{2}$ into methane), and methane have a very similar content to natural gas (usually, the content of methane exceeds $95 \% \mathrm{~mol}$ ), and because of this there are no direct problems with the transfer of synthetic methane; however, hydrogen requires additional processing, which significantly increases the cost of the manufactured product.

Gas quality standards are specific for each country; however, discussions are underway about the unification of standards across European countries [17], [18]. In some cases, the restrictions may be more stringent than necessary and may be revised [17]. For example, in the United Kingdom the allowable limit for a hydrogen blend is $0.1 \mathrm{vol} \%$, but in the Netherlands blends of up to $12 \mathrm{vol} \%$ are allowed [6].

A review of the literature related to safety requirements for hydrogen blending shows that no analyses have been conducted on the impact of hydrogen blending on grid gas quality. The reasons for this may include minor impacts and no reasonable basis for taking these impacts into account. This article evaluates the hypothesis that hydrogen blending will not have a significant impact (critical hydrogen blending levels will remain above $25 \%$ mol) on main grid gas requirements.

The aim of the article is to determine what amount of hydrogen in $\%$ mol can be transferred/stored in the Estonian, Latvian and Lithuanian grid gas networks, based on the limitations of chemical and physical requirements, technical requirements of the gas network, and quality requirements. 


\section{Methods ANd Methodology}

The characteristics of new gas fuels and products differ from those of natural gas. When hydrogen, syngas and bio-methane are added to the transmission network, the composition and characteristics of the mixture change. Understanding the properties of individual elements and their mixtures is necessary to ensure the sustainability of gas supply elements and eliminate the possibility of additional hazards.

A prerequisite for adding gas to the gas network is compliance with the requirements for the quality and characteristics of gas. The network gas quality requirements established and published by the company that owns the network the gas is planned to be transferred to, must comply with the recommendations of the European standard EN 16726:2015+A1:2018 and consumer gas installations that are part of the network.

The quality requirements for the gas supplied to the Estonian gas system are established on the basis of the laws and regulations of Estonia, Latvia and Lithuania.

The purpose of establishing and maintaining quality requirements is to ensure that the quality of the network gas matches the characteristics of the gas used in the respective existing gas equipment and to prevent damage to the gas network and equipment by corrosive liquids and pollutants. Meeting quality requirements is essential for the transfer of gas from new supply sources to gas transmission networks.

The content of natural gas, which determines its characteristics as relatively stable, can be derived from the gas quality certificate. The characteristics of hydrogen are also well-known. Assuming that, in principle, the hydrogen produced does not contain other components, its content can be considered stable. However, in some cases, hydrogen may contain other components that can affect the characteristics of the natural gas/hydrogen mixture. Under these circumstances, it is necessary to conduct a separate analysis. Therefore, we assume that the hydrogen added to the network gas contains no other components.

When setting the limit value of the added hydrogen, we proceed from normal conditions (in the context of this paper, the temperature of the gas is $20{ }^{\circ} \mathrm{C}$ at an absolute pressure of $101.325 \mathrm{kPa})$.

The main characteristics for the analysis of gas mixtures are the Wobbe Index, relative density, methane number, and calorific value. According to Estonian, Latvian and Lithuanian regulations on grid gas quality [19]-[21] the characteristics are as follows:

Calorific value is the maximum amount of energy obtained from the combustion of network gas or unit of mass. The calorific value is necessary to calculate the energy of the gas supplied and discharged from the network, as well as the Wobbe Index. The maximum allowable calorific value is $>9.69 \mathrm{kWh} / \mathrm{m}^{3}$. Calorific value, relative density, partial volume up to C6 and noble gases are obtained from gas chromatography measurements.

Relative density. The allowed range is $0.55-0.7$ for Latvia and Lithuania, and $0.55-0.75$ for Estonia. It is calculated using a gas chromatography controller according to the respective content.

Wobbe number. The allowed range of Wobbe values is $(13.06-14.44) \mathrm{kWh} / \mathrm{m}^{3}$. The Wobbe Index is an indicator of gas interchangeability that is used to compare the energy output during the combustion of fuel gases with different contents in an installation. The Wobbe Index is calculated based on the amount of network gas expressed per calorific value and relative density.

Methane number's allowed limit range is $>65$. Keeping the methane number limit value higher is necessary because in Estonia, network gas is used as motor fuel (compressed gas at filling stations). The methane number of the network gas is the same as the octane number of gasoline and the indicated marginal value must prevent knocking in gas engines. A low methane number is associated with a higher proportion of hydrocarbons in the gas. The 
methane number is calculated according to Standard EN 16726:2015+A1:2018 using gas chromatography measurements.

The analysis of gas mixtures conducted as part of this research project was performed on the basis of a simplified MS Excel model.

The input data required for calculations are given in Table 1 and Table 2.

TABLE 1. InPUT DATA FOR CALCULATING GAS MiXTuRe PARAMETERS

\begin{tabular}{lll}
\hline Name & Value & Unit \\
\hline Temperature (reference measuring conditions), $t_{m}$ & 20 & ${ }^{\circ} \mathrm{C}$ \\
Pressure (reference measuring conditions), $p_{m}$ & 101.325 & $\mathrm{kPa}$ \\
Universal gas constant, $R$ & 8.31446 & $\mathrm{~J} /(\mathrm{mol} \cdot \mathrm{K})$ \\
Air density at reference measuring conditions, $\rho^{\text {air }}{ }_{m}$ & 1.205 & $\mathrm{~kg} / \mathrm{m}^{3}$ \\
Molar composition of reference air, $M_{\text {air }}$ & 28.96546 & $\mathrm{~g} / \mathrm{mol}$ \\
Compression factor of dry air of reference composition at & 0.999645 & \\
reference measuring conditions, $Z_{\text {air, } m}$ & 12.011 & \\
Molar mass of carbon, $M_{C}$ & 1.00794 & $\mathrm{~g} / \mathrm{mol}$ \\
Molar mass of hydrogen, $M_{H}$ & $\mathrm{~g} / \mathrm{mol}$ \\
Molar mass of oxygen, $M_{O}$ & 15.9994 & $\mathrm{~g} / \mathrm{mol}$ \\
Molar mass of nitrogen, $M_{N}$ & 14.0067 & $\mathrm{~g} / \mathrm{mol}$ \\
\hline
\end{tabular}

TABLE 2. INITIAL INPUTS FOR GRID GAS COMPONENTS

\begin{tabular}{lll}
\hline Component & Summation factor, $\boldsymbol{s}_{i}$ & Gross calorific value $H_{\text {mole }}^{\text {real } \text { gross }^{,}, \mathbf{k J} / \mathbf{m o l}}$ \\
\hline Methane & 0.04317 & 890.58 \\
Ethane & 0.08950 & 1560.69 \\
Propane & 0.13080 & 2219.17 \\
n-butane & 0.17850 & 2877.40 \\
2-methylpropane & 0.16730 & 2868.20 \\
Nitrogen & 0.01560 & 0.00 \\
Carbon dioxide & 0.07300 & 0.00 \\
2,2-dimethylpropane & 0.19790 & 3514.61 \\
2-methylbutane & 0.21890 & 3528.83 \\
n-pentane & 0.22950 & 3535.77 \\
Hydrogen & -0.01000 & 285.83 \\
Hydrocarbon fractions $\mathrm{C}_{6}$ and above & 0.29070 & 4194.95 \\
\hline Exact hydrocarbon fractions $\mathrm{C}_{6}$ and above are not given. Values used are based on hexane properties.
\end{tabular}

${ }_{1}^{1}$ Exact hydrocarbon fractions $\mathrm{C}_{6}$ and above are not given. Values used are based on hexane properties.

The list of grid gas components in Table 2 was taken from [22]. The summation factors, as well as the gross calorific values for grid gas components were taken from the standard [23].

The molar volume of gas at reference measuring conditions is calculated using Eq. (1).

$$
V_{m}=Z_{m} \cdot R \cdot \frac{\left(t_{m}+273.15\right)}{p_{m}},
$$

where 
$V_{m} \quad$ Molar volume of gas under normal conditions, $\mathrm{m}^{3} / \mathrm{kmol}$;

$R \quad$ Universal gas constant, $\mathrm{J} /(\mathrm{mol} \cdot \mathrm{K})$;

$t_{m} \quad$ Temperature (reference measuring conditions), ${ }^{\circ} \mathrm{C}$;

$Z_{m} \quad$ Compression factor under reference measuring conditions;

$p_{m} \quad$ Pressure (reference measuring conditions), $\mathrm{kPa}$.

The compression factor is calculated using Eq. (2).

$$
Z_{m}=1-\left(\frac{p_{m}}{p_{0}}\right) \cdot \sum_{i=1}^{n} c_{i} \cdot s_{i},
$$

where

$p_{0} \quad$ Absolute pressure $(101.325 \mathrm{kPa})$;

$s_{i} \quad$ Summation factor at reference measuring conditions;

$c_{i} \quad$ Mole fraction of component $i$.

The numerical values of $s_{i}$ under reference measuring conditions were taken from the standard [23] and are shown in Table 2.

The molar mass $M_{i}$ of the gas component $i$ of the transmission grid (general component formula: $\mathrm{C}_{X i} \mathrm{H}_{Y i} \mathrm{O}_{W i}$ is determined using Eq. (3). In this equation, the molecular weight of the component is the sum of the molecular weights of all elements in the component, which is determined by multiplying the number of atoms of each type in the formula by its corresponding atomic weight.

$$
M_{i}=X_{i} \cdot M_{C}+Y_{i} \cdot M_{H}+Z_{i} \cdot M_{N}+W_{i} \cdot M_{O},
$$

where

$M_{i} \quad$ Molar mass of the gas component $i$ of the transmission grid, g/mol;

$X_{i} \quad$ Number of carbon atoms in the component $i$ formula;

$M_{C} \quad$ Molar mass of carbon, $\mathrm{g} / \mathrm{mol}$;

$Y_{i} \quad$ Number of hydrogen atoms in the component $i$ formula;

$M_{H} \quad$ Molar mass of hydrogen, g/mol;

$Z_{i} \quad$ Number of nitrogen atoms in the component $i$ formula;

$M_{N} \quad$ Molar mass of nitrogen, $\mathrm{g} / \mathrm{mol}$;

$W_{i} \quad$ Number of oxygen atoms in the component $i$ formula;

$M_{O} \quad$ Molar mass of oxygen, $\mathrm{g} / \mathrm{mol}$.

The gross calorific value of the grid gas on a molar basis at a combustion reference temperature $\left(25^{\circ} \mathrm{C}\right)$ of a mixture of known composition is calculated using Eq. (4):

$$
H_{\text {mole }}^{\text {ideal,gross }}=H_{m o l e}^{\text {real,gross }}=\sum_{i=1}^{n} c_{i} \cdot H e_{i}
$$

where

$H_{\text {mole }}^{\text {ideass }}$ Ideal-gas gross molar-basis calorific value of the grid gas mixture, $\mathrm{kJ} / \mathrm{mol}$;

$H_{\text {mole }}^{\text {real,gross }}$ Real-gas gross calorific value on a molar basis of the grid gas mixture, $\mathrm{kJ} / \mathrm{mol}$;

$H e_{i} \quad$ Ideal gross calorific value on a molar basis of component $i$.

Numerical values of $H e_{i}$ for a reference combustion temperature of $25^{\circ} \mathrm{C}$ are taken from the standard [23] and presented in Table 2. 
The gross calorific value on a real-gas volume basis at a combustion temperature of $25^{\circ} \mathrm{C}$, measured under reference measuring conditions, is calculated using Eq. (5):

$$
H_{\text {vol }}^{\text {real, gross }}=\frac{H_{\text {mole }}^{\text {ideal,gross }}}{V_{m} \cdot 3.6},
$$

where

$H_{v o l}^{\text {real,gross }}$ Real-gas gross volume-basis calorific value of the grid gas mixture, $\mathrm{kWh} / \mathrm{m}^{3}$;

$V_{m} \quad$ Molar volume of gas under reference measuring conditions, $\mathrm{m}^{3} / \mathrm{kmol}$.

The density of the real gas under reference measuring conditions is calculated using Eq. (6):

$$
\rho_{n}^{\text {real }}=\frac{\sum_{i=1}^{n} c_{i} \cdot M_{i}}{V_{m}},
$$

where

$\rho_{n}{ }^{\text {real }}$ Density of the ideal gas under reference measuring conditions, $\mathrm{m}^{3} / \mathrm{kmol}$;

$M_{i} \quad$ Molar mass of the grid gas component $i$;

$V_{m} \quad$ Molar volume of gas under normal conditions, $\mathrm{m}^{3} / \mathrm{kmol}$.

The Wobbe Index is calculated using Eq. (7):

$$
I_{w}=\frac{H_{v o l}^{\text {real,gross }}}{\sqrt{G_{s}}},
$$

where

$I_{w} \quad$ Wobbe Index;

$H_{\text {vol, }}^{\text {reaross }}$ Gross heat of combustion of the grid gas, $\mathrm{kWh} / \mathrm{m}^{3}$;

$G_{s} \quad$ Specific gravity.

Specific gravity $G_{s}$ is calculated using Eq. (8):

$$
G_{s}=\frac{\sum_{i=1}^{n} c_{i} \cdot M_{i}}{M_{a i r}} \cdot \frac{Z_{a i r, m}}{Z_{m}},
$$

where

$Z_{m} \quad$ Compression factor under reference measuring conditions;

$M_{\text {air }} \quad$ Molar composition of reference air, $\mathrm{g} / \mathrm{mol}$;

$Z_{\text {air }, m}$ Compression factor of dry air (reference composition) under reference measuring conditions.

The applicability and similarity of the proposed calculation results with the actual values from the grid gas quality report are validated by comparing the calculated values of the gross heat of combustion and density of the real gas under reference measuring conditions, as well as specific gravity and the Wobbe Index with the values from the quality report. 


\section{Results}

\subsection{Model Validation}

Model validation is based on the comparison of the values from the official grid gas report with the calculated values based on the approach proposed in Section 2. Methods and Methodology, where the input data for the calculation (molar composition and reference conditions) are the same as in the official grid gas report.

The examination of monthly grid gas quality reports shows that gas quality indicators and composition are quite stable. The July 2020 grid gas quality report (representative of the grid gas quality) was taken as a reference. The mole fraction of the grid gas components is shown in Table 3.

Table 3. Mole Fraction of GRID Gas Components

\begin{tabular}{|c|c|c|}
\hline Component & Value & Unit \\
\hline Methane & 95.855 & $\%_{\text {mol }}$ \\
\hline Ethane & 2.398 & $\%_{\text {mol }}$ \\
\hline Propane & 0.652 & $\%$ mol \\
\hline n-butane & 0.099 & $\%_{\text {mol }}$ \\
\hline 2-methylpropane & 0.103 & $\%$ mol \\
\hline Nitrogen & 0.676 & $\%$ mol \\
\hline Carbon dioxide & 0.175 & $\%_{\text {mol }}$ \\
\hline 2,2-dimethylpropane & 0 & $\%$ mol \\
\hline 2-methylbutane & 0.018 & $\%_{\text {mol }}$ \\
\hline n-pentane & 0.0120 & $\%$ mol \\
\hline hydrocarbon fractions $\mathrm{C}_{6}$ and above $\mathrm{e}^{1}$ & 0.0120 & $\%$ mol \\
\hline
\end{tabular}

${ }^{1}$ Exact hydrocarbon fractions $\mathrm{C}_{6}$ and above are not given. The values used are based on the properties of hexane.

A comparison of the calculated grid gas properties based on the mole fraction of grid gas components presented in the corresponding grid gas quality report is shown in Table 4.

TABLE 4. COMPARISON OF SELECTED CALCULATED AND REPORTED GRID GAS QUALITY PROPERTIES

\begin{tabular}{llll}
\hline Property & $\begin{array}{l}\text { Value from the gas } \\
\text { quality report }\end{array}$ & $\begin{array}{l}\text { Calculated } \\
\text { value }\end{array}$ & Unit \\
\hline Gross heat of combustion & 10.56 & 10.56 & $\mathrm{kWh} / \mathrm{m}^{3}$ \\
Density & 0.6999 & 0.6999 & $\mathrm{~kg} / \mathrm{m}^{3}$ \\
Specific gravity & 0.5811 & 0.5810 & \\
Wobbe Index & 13.85 & 13.86 & $\mathrm{kWh} / \mathrm{m}^{3}$ \\
\hline
\end{tabular}

Comparing the calculated and reported results from Table 5, we can see that the assumed calculation principles and the formulas used to estimate specific gravity, the Wobbe Index, gross heat of combustion and density of the real gas under reference measuring conditions are performing as expected. 


\subsection{Impact of Hydrogen Blending on Grid Gas Quality Properties}

The impact of hydrogen blending on specific gravity, the Wobbe Index, gross heat of combustion and density of the real grid gas is calculated based on the equation given in Section 2 and the distribution of grid gas components shown in Table 4. The Wärtsila Methane Number Calculator was used to illustrate the effect of hydrogen blending on the methane number of the grid gas.

Calculations were conducted for hydrogen blending levels from 0 to $50 \%$ (mole fraction). The mole fractions of other components are reduced proportionally based on the hydrogen blending level. The calculation results are presented in Table 5.

TABLE 5. IMPACT OF HydRogen BLENDING ON KEY GRID GAS QuALITy PROPERTIES

\begin{tabular}{llccccccccc}
\hline \multirow{2}{*}{ Property } & \multirow{2}{*}{$\begin{array}{c}\text { Acceptable } \\
\text { value }\end{array}$} & \multicolumn{8}{c}{ Hydrogen and natural gas blend, $\mathbf{\%}_{\mathbf{m o l}} \mathbf{H}_{\mathbf{2}}$} \\
\cline { 3 - 11 } & $\mathbf{0}$ & $\mathbf{2}$ & $\mathbf{5}$ & $\mathbf{1 0}$ & $\mathbf{1 5}$ & $\mathbf{2 0}$ & $\mathbf{3 0}$ & $\mathbf{4 0}$ & $\mathbf{5 0}$ \\
\hline $\begin{array}{l}\text { Gross calorific } \\
\text { value, } \mathrm{kWh} / \mathrm{m}^{3}\end{array}$ & $>9.69$ & 10.56 & 10.42 & 10.2 & 9.83 & 9.46 & 9.10 & 8.37 & 7.65 & 6.92 \\
$\begin{array}{l}\text { Wobbe Index, } \\
\mathrm{kWh} / \mathrm{m}^{3}\end{array}$ & $13.06-14.44$ & 13.86 & 13.79 & 13.69 & 13.51 & 13.34 & 13.16 & 12.82 & 12.48 & 12.15 \\
Specific gravity & $0.55-0.7$ & 0.58 & 0.57 & 0.56 & 0.53 & 0.50 & 0.48 & 0.43 & 0.38 & 0.33 \\
Methane number & $>65$ & 86 & 84 & 81 & 76 & 72 & 67 & -1 & & \\
\hline
\end{tabular}

${ }^{1}$ Value outside validity range (methane $=70-100 \%$ mol $)$.

The calculation results are presented graphically in Figs. 1-4. The highlighted green area shows the allowable limits according to the grid gas requirements. If the level of hydrogen blending is outside this area, this means that the mixture is outside the safety zone established by the legal acts. The impact of exceeding the values of this specific parameter (for example, the gross heat of combustion) should be analysed separately (if the required blending level does not correspond to the safety area limits) and possible changes to legal acts must be evaluated. The acceptable hydrogen and natural gas blend level is determined to some extent on the basis of assumptions (assumed values are shown by the dashed line).

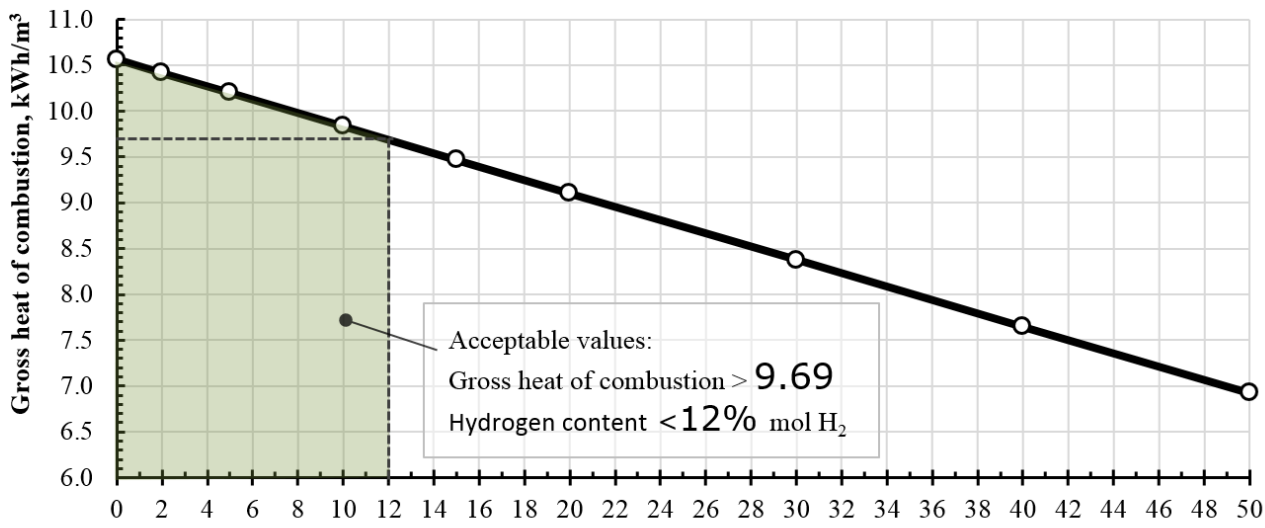

Hydrogen and natural gas blend, $\% \mathrm{~mol}_{2}$

Fig. 1. Gross heat of combustion based on hydrogen content. 


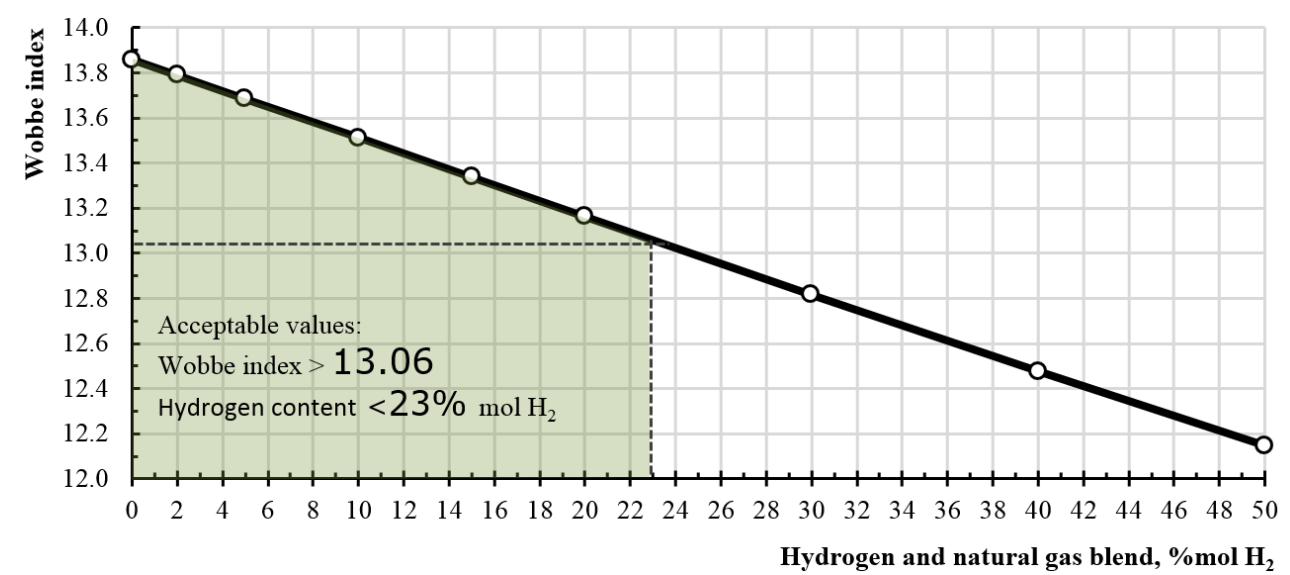

Fig. 2. Wobbe Index based on hydrogen content.

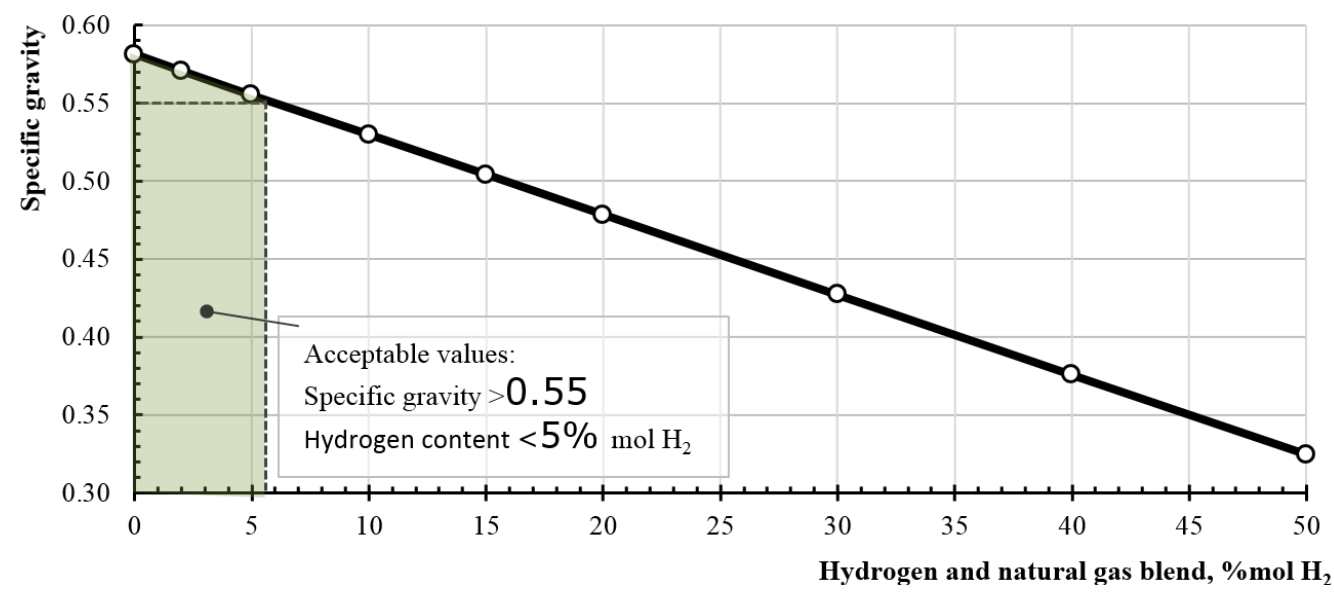

Fig. 3. Specific gravity based on hydrogen content.

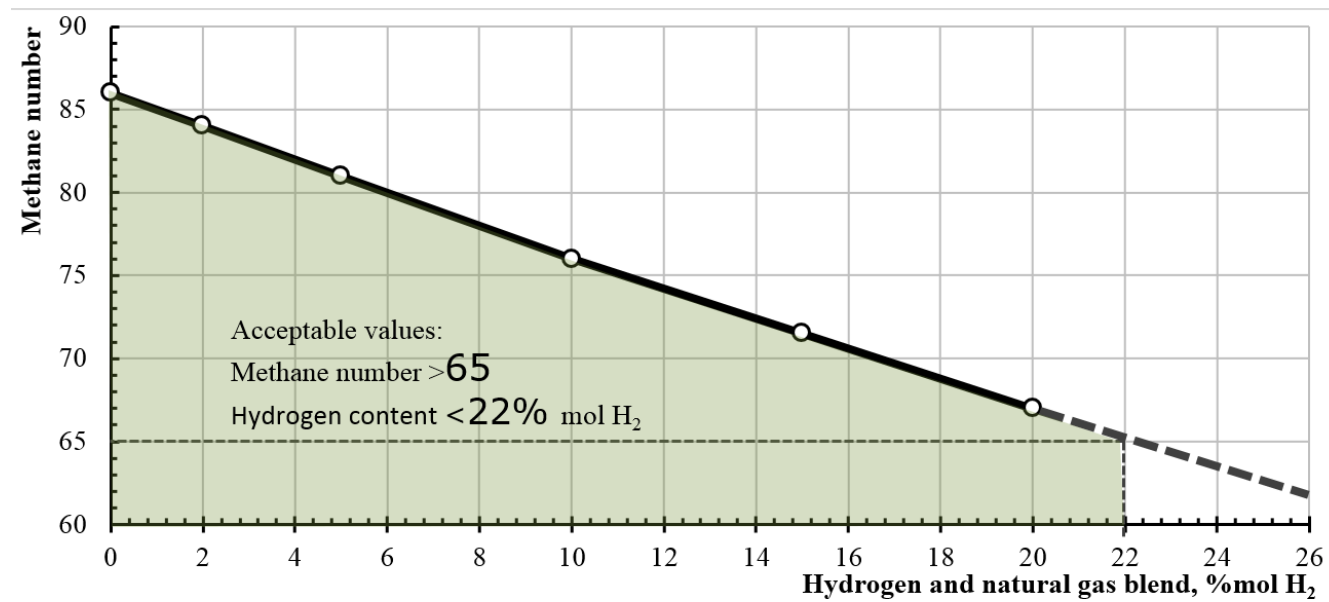

Fig. 4. Methane number based on hydrogen content. 
According to Figs. 1-4, the maximum hydrogen content in the grid gas (hydrogen and natural gas blend) depends on the grid gas quality parameters (methane number, gross heat of combustion, specific gravity, and the Wobbe Index) and is in the range of $5-23 \% \mathrm{~mol} \mathrm{H}_{2}$. The minimum hydrogen content $\left(5 \% \mathrm{~mol}_{2}\right)$ is limited by specific gravity $(>0.55)$.

\section{Discussion ANd Conclusions}

Due to the difference between hydrogen and natural gas, mixtures of hydrogen and natural gas create additional hazards, causing corrosion and increasing the risk of explosion and fire in transmission pipelines and end-user installations.

Hydrogen blending limitations are also related to the requirements for grid gas quality properties (legislative restrictions). The main grid gas quality properties affected by hydrogen blending are methane number, gross heat of combustion, specific gravity, and the Wobbe Index.

A methodology for calculating the effect of hydrogen on a hydrogen-natural gas mixture is presented in the paper. The applicability and similarity of the proposed calculation results with the actual values from the grid gas quality report are validated by comparing the calculated values with the values from the quality report. Comparing the calculated and reported results, we can see that the assumed calculation principles and the formulas used are performing as expected.

The calculation results show that the maximum hydrogen content in the grid gas (hydrogen and natural gas blend), depending on the grid gas quality parameters (methane number, gross heat of combustion, specific gravity, and the Wobbe Index), is in the range of $5-23 \%$ mol $\mathrm{H}_{2}$. The minimum hydrogen content $\left(5 \% \mathrm{~mol} \mathrm{H}_{2}\right)$ is limited by specific gravity $(>0.55)$. The next limitation is at $12 \% \mathrm{~mol} \mathrm{H}_{2}$ and is related to the gross heat of combustion $\left(>9.69 \mathrm{kWh} / \mathrm{m}^{3}\right)$. It can be stated that the impact of hydrogen blending on the main qualitative characteristics of the grid gas mixture is significant and can be a limiting factor for hydrogen blending starting at $5 \%$ mol.

It is reasonable to investigate the readiness of the Estonian, Latvian and Lithuanian gas grids and gas consumers to switch to high-level hydrogen blends. If the applicability and safety of hydrogen blends above $5 \% \mathrm{~mol}$ are approved, then a possible reduction in the minimum requirements for the quality of the grid gas should be analysed, and the associated risks (primarily for specific gravity) should be assessed.

\section{REFERENCES}

[1] Blumberga A., Timma L., Blumberga D. System dynamic model for the accumulation of renewable electricity using Power-to-Gas and Power-to-Liquid concepts. Environmental and Climate Technologies 2015:16:54-68. https://doi.org/10.1515/rtuect-2015-0012

[2] Gonzalez Diez N., et al. North Sea Energy Technical assessment of Hydrogen transport, compression, processing offshore. As part of Topsector Energy: TKI Offshore Wind \& TKI New Gas. Denmark: NSE, 2020.

[3] Shang J., et al. Enhanced hydrogen embrittlement of low-carbon steel to natural gas/hydrogen mixtures. Scripta Materialia 2020:189:67-71. https://doi.org/10.1016/j.scriptamat.2020.08.011

[4] Marcogaz. Overview of Available Test Results and Regulatory Limits for Hydrogen Admission into Existing Natural Gas Infrastructure and End Use. Brussels: Macrogaz, 2019.

[5] Technical and economic conditions for injecting hydrogen into natural gas networks. Final report, June 2019.

[6] Quarton C. J., Samsatli S. Power-to-gas for injection into the gas grid: What can we learn from real-life projects, economic assessments and systems modelling? Renewable and Sustainable Energy Reviews 2018:98:302-316. https://doi.org/10.1016/j.rser.2018.09.007

[7] Leicher J., et al. Hydrogen in natural gas: how does it impact industrial end users. Proceedings of the World Gas Conference 2018. 
[8] Ogden J., et al. Natural gas as a bridge to hydrogen transportation fuel: Insights from the literature. Energy Policy 2018:115:317-329. https://doi.org/10.1016/j.enpol.2017.12.049

[9] Tlili O., et al. Geospatial modelling of the hydrogen infrastructure in France in order to identify the most suited supply chains. International Journal of Hydrogen Energy 2020:45(4):3053-3072. https://doi.org/10.1016/j.ijhydene.2019.11.006

[10] Reuß M., et al. A hydrogen supply chain with spatial resolution: Comparative analysis of infrastructure technologies in Germany. Applied Energy 2019:247:438-453. https://doi.org/10.1016/j.apenergy.2019.04.064.

[11] Kleperis J., et al. Analysis of the Role of the Latvian Natural Gas Network for the use of Future Energy Systems: Hydrogen from Res. Latvian Journal of Physics and Technical Sciences 2021:58:214-226. https://doi.org/10.2478/lpts-2021-0027.

[12] Gondal I. A. Hydrogen integration in power-to-gas networks. International Journal of Hydrogen Energy 2019:44(3):1803-1815. https://doi.org/10.1016/j.ijhydene.2018.11.164.

[13] Rigas F., Amyotte P. Myths and facts about hydrogen hazards. Chemical Engineering Transactions 2013:31:913918. https://doi.org/10.3303/CET1331153.

[14] Messaoudani Z., et al. Hazards, safety and knowledge gaps on hydrogen transmission via natural gas grid: A critical review. International Journal of Hydrogen Energy 2016:41(39):17511-17525. https://doi.org/10.1016/j.ijhydene.2016.07.171.

[15] EIGA. Hydrogen transportation pipelines. IGC Doc 121/04/E 2004:77.

[16] HySafe. Chapter V: Hydrogen Safety Barriers and Safety Measures. Biennial Report on Hydrogen Safety. Eggenstein-Leopoldshafen: Forschungszentrum Karlsruhe, 2006.

[17] Speirs J., et al. A greener gas grid: what are the options? Energy Policy 2018:118:291-297. https://doi.org/10.1016/j.enpol.2018.03.069

[18] Pöyry GND. Gas quality harmonisation cost benefit analysis: final report. Loughborough: DNV, 2012.

[19] İsakymas dèl gamtinių dujų kokybės reikalavimų patvirtinimo (Quality Requirements for Natural Gas), Minister for Energy of the Republic of Lithuania, 04.10.2013, Nr. 1-194, Lithuania

[20] Gaasituru toimimise võrgueeskiri (Network code for the operation of the gas market) The Minister of Economic Affairs and infrastructure 28.07.2017 nr 41, Estonia.

[21] Dabasgāzes tirdzniecības un lietošanas noteikumi (Regulations Regarding the Trade and Use of Natural Gas), Cabinet of Ministers of Latvia. Regulation No 78. Latvijas Véstnesis 2017:44.

[22] Elering AS. Average monthly gas quality. July 2020. Tallin: Elering, 2020.

[23] CEN. ISO 6976:2016. Natural gas - Calculation of calorific values, density, relative density and Wobbe indices from composition 2016. 